\title{
Pharmacokinetics, Pharmacodynamics, and Tolerability of AZD5718, an Oral 5-Lipoxygenase-Activating Protein (FLAP) Inhibitor, in Healthy Japanese Male Subjects
}

\author{
Jane Knöchel ${ }^{1}$ (1) $\cdot$ Karin Nelander ${ }^{2} \cdot$ Maria Heijer $^{1} \cdot$ Eva-Lotte Lindstedt $^{3}$. Gun-Britt Forsberg ${ }^{3} \cdot$ Carl Whatling $^{3}$. \\ Hitoshi Shimada ${ }^{4} \cdot$ David S. Han $^{5} \cdot$ Anders Gabrielsen $^{3} \cdot$ Pavlo Garkaviy $^{3} \cdot$ Hans Ericsson $^{1}$
}

Accepted: 31 August 2021 / Published online: 21 September 2021

(c) The Author(s) 2021

\begin{abstract}
Background and Objective AZD5718, a 5-lipoxygenase-activating protein (FLAP) inhibitor, is in clinical development for treatment of coronary artery disease (CAD) and chronic kidney disease (CKD). This study evaluated AZD5718 pharmacokinetics, pharmacodynamics, and tolerability in healthy male Japanese subjects.

Methods Four cohorts of eight Japanese subjects were randomized to receive oral doses of AZD5718 (60, 180, 360, and $600 \mathrm{mg}$ ) or matching placebo administered as a single dose on Day 1 and as once-daily doses from Day 3 to Day 10 in fasted conditions. Pharmacokinetic, pharmacodynamic, and safety data were collected.

Results The pharmacokinetics characteristics of AZD5718 in Japanese male subjects were similar to those reported in a previous study, and the pharmacokinetics were characterized as rapid absorption with median time to reach maximum concentration $\left(T_{\max }\right)$ of 1-2 $\mathrm{h}$ Creatine-normalized urine maximum concentration $\left(C_{\max }\right)$ with mean half-lives ranging from 8 to $21 \mathrm{~h}$, and supra-proportional increase in exposure over the 60-600 mg dose range evaluated. Also, an increase in steady-state area under the concentration-time curve (AUC) compared to the first dose was observed. After both single and multiple doses of AZD5718, a clear dose/concentration-effect relationship was shown for urinary leukotriene $\mathrm{E}_{4}\left(\mathrm{LTE}_{4}\right)$ versus AZD5718 exposure with $>80 \%$ inhibition at plasma concentrations in the lower $\mathrm{nM}$ range. No clinically relevant safety and tolerability findings were observed.

Conclusions The observed pharmacokinetics and pharmacodynamics were similar to reported data for non-Japanese healthy subjects, which support further evaluation of AZD5718 at similar doses/exposures in Japanese and non-Japanese subjects for future evaluation in patients with CAD and CKD.
\end{abstract}

Jane Knöchel

jane.knochel@astrazeneca.com

1 Clinical Pharmacology and Quantitative Pharmacology, Clinical Pharmacology and Safety Sciences,

BioPharmaceuticals R\&D, AstraZeneca, Pepparedsleden 1, Mölndal, 43183 Gothenburg, Sweden

2 Early Biometrics and Statistical Innovation, Data Science and AI, BioPharmaceuticals R\&D, AstraZeneca, Gothenburg, Sweden

3 Research and Early Development, Cardiovascular, Renal and Metabolism, BioPharmaceuticals R\&D, AstraZeneca, Gothenburg, Sweden

4 Science Enablement, Science and Data Analytics, Japan R\&D, AstraZeneca, Osaka, Japan

5 PAREXEL Early Phase Clinical Unit, Los Angeles, CA, USA

\section{Key Points}

AZD5718 was well tolerated in healthy Japanese subjects.

The pharmacokinetics and pharmacodynamics in healthy Japanese subjects were similar to those reported in nonJapanese healthy subjects.

The study results support the development of similar doses of AZD5718 in Japanese and non-Japanese coronary artery disease and chronic kidney disease patients. 


\section{Introduction}

Five-lipoxygenase (5-LO)-activating protein (FLAP) is critical for the production of inflammatory and vasoactive leukotrienes by the 5-LO pathway and has been genetically associated with an increased risk of myocardial infarction [1]. It is hypothesized that inhibition of FLAP activity will reduce mortality, morbidity, and cardiovascular hospitalization in cardiovascular disease (CAD) patients by attenuation of proinflammatory and vasoactive leukotriene production in the coronary circulation. Leukotrienes have also been implicated in the etiology of chronic kidney disease (CKD) both through pro-inflammatory leukotriene $\mathrm{B}_{4}$ $\left(\mathrm{LTB}_{4}\right)$ and through vascular mechanisms (leukotriene $\mathrm{C} 4$ $\left(\mathrm{LTC}_{4}\right) /$ leukotriene $\left.\mathrm{D}_{4}\left(\mathrm{LTD}_{4}\right)\right)$ [2,3]. Inflammation has been recognized as a key component of diabetic nephropathy, and increased expression of the 5-LO and FLAP genes in the tubulointerstitial compartment in subjects with CKD has been observed, indicating the potential for an increased inflammatory leukotriene drive [4].

AZD5718 is a potent and selective inhibitor of leukotriene production. It binds reversibly and with high affinity to cell membranes expressing FLAP in vitro and potently suppresses leukotriene production in human whole blood [5]. Several FLAP inhibitors have previously been evaluated in the clinic and shown to inhibit $\mathrm{LTB}_{4}$ production in blood stimulated ex vivo and to suppress $\mathrm{LTE}_{4}$ levels in urine [6-8]. However, none of these earlier compounds progressed to become developed drugs for diverse reasons including too low potency, lack of efficacy in the clinical indication evaluated, and/or tolerability and toxicity issues [9]. To our knowledge, AZD5718 is the only FLAP inhibitor currently in clinical development; it is the second FLAP inhibitor intended to be developed for treatment of patients with CAD and the first for treatment of patients with CKD.

The safety, tolerability, and pharmacokinetics of AZD5718 have been evaluated in a single- and multipleascending dose (SMAD) study in fasting and fed healthy volunteers [10]. Also, a study evaluating the relative bioavailability of different tablet formulations as well as potential drug interaction with rosuvastatin has been reported [11]. In the SMAD study, AZD5718 was well tolerated. No clinically meaningful differences for changes over time in clinical laboratory tests, vital signs, or electrocardiograms (ECGs) were observed between healthy volunteers who received AZD5718 and those who received placebo. Following suspension administration of AZD5718, the compound was rapidly absorbed and maximum plasma concentration $\left(C_{\max }\right)$ was generally reached within $1-2 \mathrm{~h}$. Administration of $180 \mathrm{mg}$ AZD5718 together with food reduced the total exposure (AUC) and $C_{\max }$. In addition, time to reach $C_{\max }\left(T_{\max }\right)$ was longer when dosed together with food but the concentration at the end of the dosing interval at steady-state $\left(C_{\text {trough }}\right)$ values were similar when dosed in the fed state compared to dosing in the fasted state. In the dose range evaluated, a more than dose-proportional increase in both AUC and $C_{\max }$ was observed, whereas $C_{\text {trough }}$ appeared to increase in a dose-proportional manner. In agreement with the terminal half-life of $10 \mathrm{~h}$, steady-state levels were achieved after 2-3 days after oncedaily dosing. The study evaluating different tablet formulations reported AZD5718 oral suspension and immediaterelease tablets had different pharmacokinetic profiles but were predicted in pharmacodynamic models to have the same inhibitory effects on the production of leukotriene $B_{4}$ $\left(\mathrm{LTB}_{4}\right)$ in blood [11]. Also, coadministration of AZD5718 with rosuvastatin had no clinically relevant effect on the pharmacokinetic profiles of either drug [11].

In early drug development it is important that differences in response in pharmacokinetics, pharmacodynamics, or safety associated with ethnic origin are identified in order to guide future studies. Based on the AZD5718 compound characteristics including pharmacokinetic properties and mechanism of action, no or minor ethnic differences were anticipated, but this needed to be proven. Thus, the objectives of this study were to evaluate the safety, tolerability, pharmacokinetics, and pharmacodynamics of AZD5718 in healthy Japanese subjects and to compare the results with a similar study in healthy non-Japanese subjects in order to guide the clinical development program of AZD5718 in CAD or CKD patients of Japanese origin.

\section{Patients and Methods}

\subsection{Study Design}

This study was a multiple-ascending study (MAD) in healthy male Japanese subjects performed at a single study center (NCT03400488) conducted between 15 January 2018 and 12 June 2018. The study was of a randomized, single-blind, placebo-controlled, MAD sequential group design with no sentinel dosing schedule applied. A total of four cohorts were included and within each six subjects were dosed with AZD5718 suspension and two subjects were dosed with placebo suspension. The design was similar to that reported in the study in non-Japanese healthy subjects, which evaluated the same doses as explored in the current study [10]. However, in this study the first dose was followed for $48 \mathrm{~h}$ before repeated dosing was initiated on Day 3 and continued until Day 10. 


\subsection{Clinical Safety}

The tolerability and safety assessments involved evaluation of vital signs, ECG, telemetry, routine clinical laboratory examinations, and adverse events (AEs). An AE is the development of an undesirable medical condition or the deterioration of a pre-existing medical condition following or during exposure to a pharmaceutical product, whether or not considered causally related to the product. An undesirable medical condition can be symptoms (e.g., nausea, chest pain), signs (e.g., tachycardia, enlarged liver), or the abnormal results of an investigation (e.g., laboratory findings, electrocardiogram). In clinical studies an AE can include an undesirable medical condition occurring at any time after the subject has signed informed consent, including run-in or washout periods, even if no specific treatment has been administered. The term AE is used generally to include any $\mathrm{AE}$ whether serious or nonserious. The following intensity ratings were used: mild (awareness of sign or symptom, but easily tolerated); moderate (discomfort sufficient to cause interference with normal activities); severe (incapacitating, with inability to perform normal activities).

A serious $\mathrm{AE}$ is an $\mathrm{AE}$ occurring during any study phase (i.e., run-in, treatment, washout, follow-up) that fulfills one or more of the following criteria: results in death; is immediately life-threatening; requires in-patient hospitalization or prolongation of existing hospitalization; results in persistent or significant disability or incapacity or substantial disruption of the ability to conduct normal life functions; is a congenital abnormality or birth defect; is an important medical event that may jeopardize the subject or may require medical intervention to prevent one of the outcomes listed above.

Safety assessments were taken before and at scheduled times after dosing as well as at the follow-up visit 7-10 days post final dose administration. Safety and pharmacokinetic/ pharmacodynamic data were analyzed at safety review committee meetings before proceeding to the subsequent dose levels.

\subsection{Doses and Dosing}

The dose levels administered in this study were the same as those administered to healthy non-Japanese subjects in an earlier single-ascending dose (SAD)/MAD study [10]. In that study, all the doses were observed to be safe and well tolerated. The starting dose was $60 \mathrm{mg}$ AZD5718 and the subsequent dose steps were $180 \mathrm{mg}, 360 \mathrm{mg}$, and $600 \mathrm{mg}$. An amorphous suspension, identical to the formulation evaluated in the non-Japanese study in healthy subjects [10], was used in the present study. Before frequent pharmacokinetic sampling (after the first and the last dose on Day 10) subjects fasted for $10 \mathrm{~h}$ overnight before the morning dose. Up to 150 $\mathrm{mL}$ of water was allowed up to $1 \mathrm{~h}$ prior to each morning dose and could be resumed $1 \mathrm{~h}$ after dosing. A meal was served $4 \mathrm{~h}$ after the morning dose. On other days during the repeated dosing phase of the study, subjects fasted for $10 \mathrm{~h}$ overnight prior to the morning dose and breakfast was delayed until $2 \mathrm{~h}$ after dosing.

\subsection{Pharmacokinetic and Pharmacodynamic Assessments}

\subsubsection{Blood and Urine Sampling for Quantification of AZD5718}

Blood and urine samples for quantification of AZD5718 were collected and analyzed using the validated methods as described in Ericsson et al. [10]. Samples below the lower limit of quantification were reported as "below the lower limit of quantification." The methods demonstrated acceptable precision, accuracy, and selectivity for AZD5718 in the appropriate matrices [10], and the recoveries of AZD5718 in both plasma and urine were sufficient and reproducible across all the validated concentration ranges. The results from the in-study quality control (QC) samples and calibration standards were evaluated, and it was concluded that both methods performed acceptably for this study. The interrun accuracy for the study QC samples ranged from 94.0 to $110.0 \%$ and the inter-run precision was less than $5.9 \%$. In addition, incurred sample reproducibility (ISR) analyses were performed during the study. For determination of AZD5718 in plasma, 78 of the 78 samples (100\%) tested were within $20 \%$ of the mean of the two values. For determination of AZD5718 in urine, 21 of the 24 samples (87.5\%) tested were within $20 \%$ of the mean of the two values. Both assessments were well within the acceptance criteria. All study samples were analyzed within the validated stability period.

\subsection{2 $\mathrm{LTE}_{4}$ Quantification in Urine}

Creatine-normalized urine $\mathrm{LTE}_{4}$ levels were quantified as described in Ericsson et al. [10]. Samples were collected on Day 1 and Day 10 as spot samples pre-dose and pooled 0-3, $3-6,6-9$, and $9-12 \mathrm{~h}$ in urine, spot samples at 24 and $36 \mathrm{~h}$ post-dose, and on Day 3 to Day 9 only spot samples pre-dose were collected.

\subsubsection{Pharmacokinetic Analysis}

Two milliliters of blood were collected into tubes containing $\mathrm{K}_{2}$-EDTA as anticoagulant for each time point [10] for pharmacokinetic analyses before all doses and at $0.5,1,2$, $3,4,6,8,10,12,16,24,30,36$, and $48 \mathrm{~h}$ after the first and final dose. Urine samples were collected on Day 10 (before and $0-3,3-6,6-12$, and $12-24 \mathrm{~h}$ after dosing). Plasma 
pharmacokinetic outcomes included the observed maximum concentration $\left(C_{\max }\right)$, time to $C_{\max }\left(T_{\max }\right)$, half-life associated with the terminal slope $(\lambda z)$ of a semilogarithmic concentration-time curve $\left(\mathrm{t}_{1 / 2 \lambda \mathrm{z}}\right)$, area under the concentration-time curve extrapolated to infinity $\left(\mathrm{AUC}_{\infty}\right)$ and within the dosing period $\left(\mathrm{AUC}_{\tau}\right)$, apparent clearance $(\mathrm{CL} / F)$, and renal clearance $\left(\mathrm{CL}_{\mathrm{R}}\right)$. Actual blood sampling times were used in all analyses and plasma concentration-time data were analyzed by non-compartmental analysis with Phoenix WinNonlin version 6.4 (Pharsight Corp., Mountain View, CA, USA). The pharmacokinetic analysis set included all participants in the safety set with calculable pharmacokinetic data for at least two treatment periods and without protocol deviations that might have affected pharmacokinetic data. The AUC was calculated using the log-linear trapezoidal approach.

\subsection{Statistical Analysis}

\subsubsection{Sample Size and Pharmacokinetic Parameter Analysis}

The sample size was chosen to obtain reasonable evidence of safety and tolerability without exposing undue numbers of healthy subjects to the compound at this stage of clinical drug development. Previous experience from similar studies has shown that the sample size used was reasonable to accomplish the objectives of this study [12]. The power model denoted as $y=\alpha \times \operatorname{Dose}^{\beta}$ was used to assess dose proportionality for pharmacokinetic parameters for Day 1 and Day 10 separately. The estimates for the slope were obtained via least squares regression of the log-transformed pharmacokinetic parameters versus log-transformed dose (Eq. 1):

$\log (y)=\alpha+\beta \times \log ($ Dose $)$,

where $y$ refers to the pharmacokinetic parameter.

Time dependency on the pharmacokinetics was evaluated by comparing $\mathrm{AUC}_{\tau}$ on Day 10 with total AUC of Day 1.
Time dependency for each dose level was assessed in a linear mixed effects model with subject as random effect and dose level, day, and interaction dose-by-day as fixed effects. All pharmacokinetic parameters were log transformed in order to obtain the geometric mean ratios and the corresponding $90 \%$ confidence intervals.

\subsubsection{Comparison of Pharmacokinetics}

In order to compare Japanese pharmacokinetic characteristics to non-Japanese subjects the results of a Phase I, randomized, single-blind, placebo-controlled study [10] focusing on the MAD part were used. Log-transformed pharmacokinetic parameters $\left(C_{\max }\right.$ and $\left.\mathrm{AUC}_{\tau}\right)$ of both studies were analyzed using a least square regression with race as fixed effect for each dose level.

\section{Results}

\subsection{Subjects}

A total of 32 healthy male Japanese subjects between the ages of 21 and 49 years were included in this study. Every randomized subject completed the study, and none withdrew from the study. Mean age $( \pm$ SD) of the Japanese subjects in this study was $32.7 \pm 6.3$ years and weight $( \pm$ SD) was 65.8 $\pm 6.4 \mathrm{~kg}$. All subjects were found to be in good health based on the results of medical history, physical examination, clinical laboratory evaluations, and ECG obtained up to 28 days prior to initial study drug administration. Demographics and subject characteristics are summarized in Table 1.

\subsection{Safety and Tolerability}

No serious AEs were observed. There were a total of 19 AEs, all of which were reported to be of mild intensity. Out of these AEs, seven were associated with five subjects

Table 1 Summary of the demographics and characteristics of Japanese male subjects included in this study, $n=6$ per dose level and $n=8$ for placebo

\begin{tabular}{|c|c|c|c|c|c|c|c|}
\hline Variable/category & Placebo & AZD5718 $60 \mathrm{mg}$ & $\begin{array}{l}\text { AZD5718 } \\
180 \mathrm{mg}\end{array}$ & AZD5718 $360 \mathrm{mg}$ & AZD5718 $600 \mathrm{mg}$ & $\begin{array}{l}\text { Total } \\
\text { AZD5718 }\end{array}$ & All subjects \\
\hline Age (years) & $34.1(7.3)$ & $32.2(5.9)$ & $29.8(6.5)$ & $31.8(6.9)$ & $35.2(5.3)$ & $32.2(6.1)$ & $32.7(6.3)$ \\
\hline Height $(\mathrm{cm})$ & $173.0(4.9)$ & $168.7(6.7)$ & $166.7(7.2)$ & $171.7(6.0)$ & $172.3(5.8)$ & $169.8(6.5)$ & $170.6(6.2)$ \\
\hline Body weight (kg) & $68.9(8.3)$ & $65.0(5.3)$ & $61.5(4.5)$ & $66.4(6.6)$ & $66.4(4.8)$ & $64.8(5.4)$ & $65.8(6.4)$ \\
\hline BMI $\left(\mathrm{kg} / \mathrm{m}^{2}\right)$ & $23.0(2.5)$ & $22.8(1.2)$ & $22.2(1.3)$ & $22.6(3.1)$ & $22.4(1.9)$ & $22.5(1.9)$ & $22.6(2.0)$ \\
\hline $\begin{array}{l}\mathrm{LTE}_{4} \text { in urine (pmol/ } \\
\text { mmol creatinine) }\end{array}$ & $27.4(10.7)$ & $18.6(6.5)$ & $24.8(9.6)$ & $25.3(8.2)$ & $43.9(24.8)$ & $28.2(16.5)$ & $28.0(15.1)$ \\
\hline
\end{tabular}

Values are given as mean (SD) for continuous variables and as total numbers (\%) for categorical variables $B M I$ body mass index, $L T E_{4}$ leukotriene $\mathrm{E}_{4}$ 
in the placebo group and 12 were observed in ten subjects in the active arms. The most frequently reported $\mathrm{AE}$ was contact dermatitis due to ECG leads (11 AEs), and single AEs of upper abdominal pain, toothache, constipation, nausea, skin abrasion, aspartate aminotransferase increase, creatine phosphokinase increase, and rhinorrhoea in eight different subjects. Overall, multiple oral doses of AZD5718 were well tolerated for all active study arms (60, 180,360 , and $600 \mathrm{mg}$ ).

Furthermore, no clinically significant trends were found in vital sign assessment, ECG measurements, telemetry, or any laboratory results.

\subsection{Pharmacokinetics and Pharmacodynamics}

Geometric mean plasma concentration-time profiles for AZD5718 in healthy Japanese subjects following oncedaily multiple oral dose administrations are shown in Fig. 1. Following multiple oral dosing, AZD5718 has a $T_{\max }$ occurring at $1-2 \mathrm{~h}$ post-dose, suggesting rapid absorption (Table 2). The rapid absorption phase is followed by a biphasic decline in plasma concentration over time. Exposure of AZD5718 increased in a supra-proportional manner with doses over the 60-600 mg daily dose range, where the supra-proportionality was most markedly observed between the 60 and $180 \mathrm{mg}$ doses (Fig. 2). The slope estimates $(90 \% \mathrm{CI})$ were $1.52(1.35,1.70)$ and
Day 1

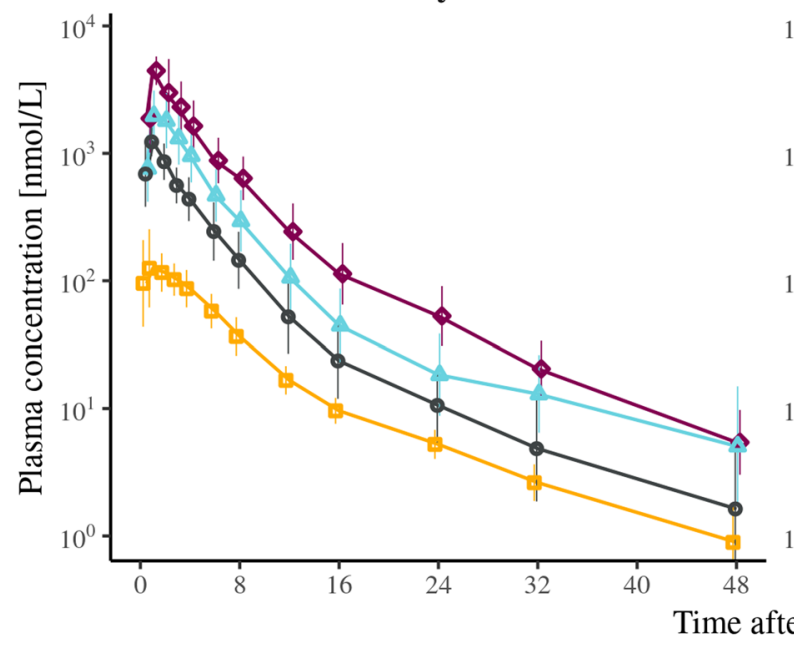

Day 10

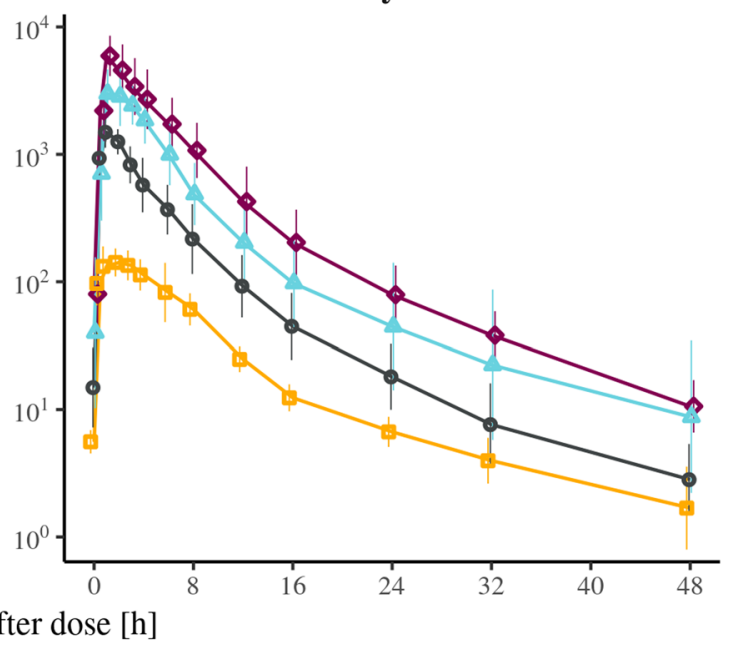

Dose $\square 60 \mathrm{mg} \quad \bullet \quad 180 \mathrm{mg} \Delta 360 \mathrm{mg} \diamond 600 \mathrm{mg}$

Fig. 1 Geometric mean \pm SD for plasma concentration-time profiles by treatment following multiple ascending doses of AZD5718 in healthy Japanese subjects (first and last dose, Day 1 and 10, respectively), $n=6$ per dose

Table 2 Summary of pharmacokinetic parameters (geometric mean with percentage of coefficient of variation), except for $T_{\max }$ median (range) following repeated oral dosing of AZD5718 in healthy Japanese subjects, $n=6$ per dose level

\begin{tabular}{|c|c|c|c|c|c|c|c|}
\hline Dose, dosing regimen, day & $C_{\max }(\mathrm{nmol} / \mathrm{L})$ & $T_{\max }(\mathrm{h})$ & $\mathrm{AUC}_{\tau}(\mathrm{nmol} \bullet \mathrm{h} / \mathrm{L})$ & $\mathrm{CL} / F(\mathrm{~L} / \mathrm{h})$ & $t_{1 / 2}(\mathrm{~h})$ & $\mathrm{CL}_{\mathrm{R}}(\mathrm{L} / \mathrm{h})$ & TCP \\
\hline 60 mg, OD, Day 1 & $140.5(55.1)$ & $1.0(1.0,3.0)$ & $862.9(35.8)$ & $142.1(33.5)$ & $10.1(44.0)$ & NE & NE \\
\hline 60 mg, OD, Day 10 & $158.9(25.1)$ & $2.0(1.0,3.0)$ & $1140.5(25.5)$ & $117.8(25.5)$ & $12.8(47.0)$ & $0.8(22.5)$ & $1.2(14.9)$ \\
\hline 180 mg, OD, Day 1 & $1277.0(24.6)$ & $1.0(0.5,2.0)$ & $4739.4(33.3)$ & $82.2(35.8)$ & $8.5(47.9)$ & NE & NE \\
\hline 180 mg, OD, Day 10 & $1567.9(28.6)$ & $1.5(1.0,2.0)$ & $6724.5(32.0)$ & $60.0(32.0)$ & $8.6(23.6)$ & $0.8(38.4)$ & $1.4(14.1)$ \\
\hline 360 mg, OD, Day 1 & $2196.3(48.6)$ & $1.0(1.0,2.1)$ & $8971.1(47.6)$ & $84.3(51.7)$ & $15.0(100.5)$ & NE & $\mathrm{NE}$ \\
\hline 360 mg, OD, Day 10 & $3461.5(40.4)$ & $2.0(1.0,3.0)$ & $15,847.3(47.8)$ & $50.9(47.8)$ & $10.5(29.1)$ & $0.9(21.0)$ & $1.7(31.9)$ \\
\hline 600 mg, OD, Day 1 & $5180.6(24.2)$ & $1.0(1.0,2.0)$ & $17,592.6(39.9)$ & $74.1(40.0)$ & $7.4(25.5)$ & NE & $\mathrm{NE}$ \\
\hline 600 mg, OD, Day 10 & $6145.6(40.0)$ & $1.0(1.0,2.0)$ & $27,349.3(48.8)$ & $49.1(48.8)$ & $8.5(35.1)$ & $0.8(16.8)$ & $1.5(28.9)$ \\
\hline
\end{tabular}

$A U C_{\tau}$ area under the concentration-time curve over the dosing interval, $C L / F$ oral plasma clearance, $C L_{R}$ renal clearance, $C_{\text {max }}$ peak plasma concentration, $N E$ not estimated, $O D$ once daily, $t_{1 / 2}$ terminal half-life, $T_{\max }$ time to peak concentration, $T C P$ temporal change parameter in systemic exposure calculated as $\mathrm{AUC}_{\tau}$ Day 10/AUC Day 1 
Fig. 2 Evaluation of doseproportionality: area under the concentration-time curve over the dosing interval (AUC $\tau)$, peak plasma concentration $\left(C_{\max }\right)$, and trough plasma concentration $\left(C_{\text {trough }}\right)$ for Japanese subjects at Day 1 and Day 10, $n=6$ per dose. The dashed line represents the linear regression fit
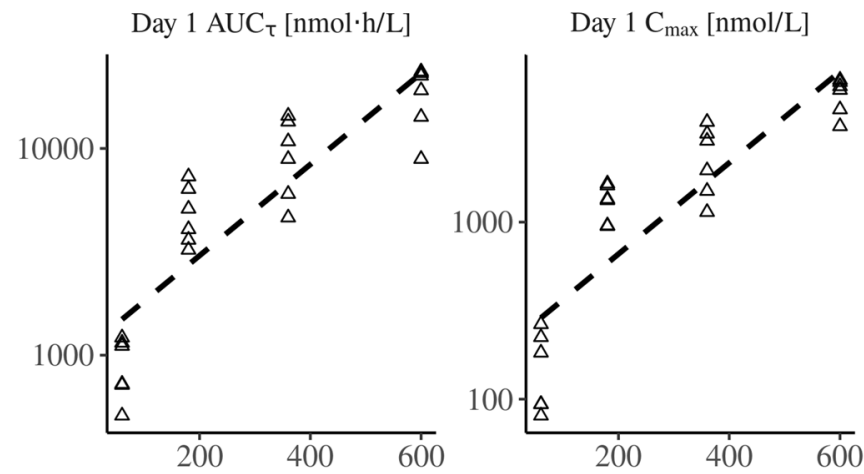

Day $1 \mathrm{C}_{\text {trough }}[\mathrm{nmol} / \mathrm{L}]$

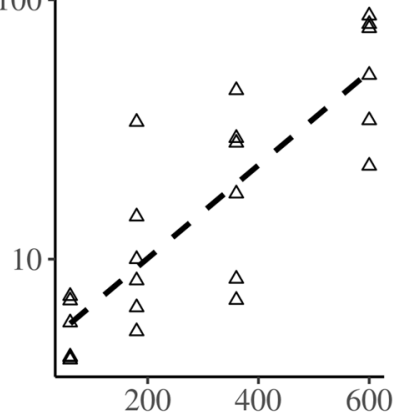

Day $10 \mathrm{C}_{\max }[\mathrm{nmol} / \mathrm{L}]$

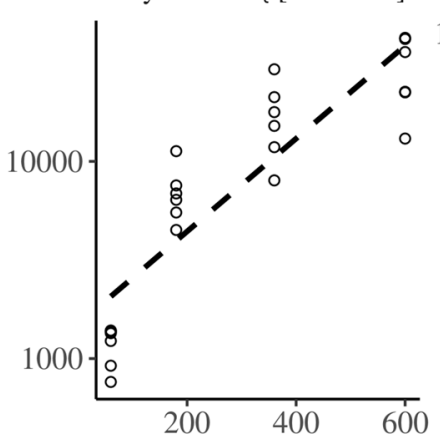

Day $10 \mathrm{C}_{\text {trough }}[\mathrm{nmol} / \mathrm{L}]$
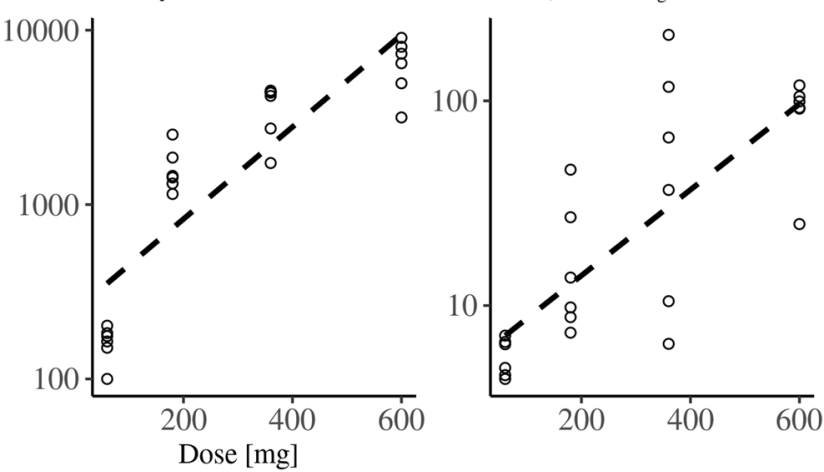

$1.27(1.11,1.43)$ for $C_{\max }$ and AUC, respectively, after a single dose, and were $1.59(1.43,1.75)$ and 1.39 (1.23, 1.54) for $C_{\max }$ and AUC, respectively, after multiple dosing. Plasma concentrations reached steady-state levels after 3-4 days of dosing. The accumulation in AUC $\tau$ was $32-77 \%$, which is mainly in accordance with the observed range of half-life and the dosing regimen; however, a slight time-dependent increase in exposure was observed in all active arms. Inter-subject variability in exposure was moderate to high following single and multiple dosing for all dose levels [13], with a slightly higher observed variability in the $360 \mathrm{mg}$ cohort most markedly in the trough concentration. Overall, the pharmacokinetic characteristics including the variability were comparable to those observed in the non-Japanese SMAD study [10].

A dose-dependent inhibition of endogenous $\mathrm{LTE}_{4}$ in urine was observed after repeated dosing of AZD5718 (Fig. 3). All doses already inhibited $\mathrm{LTE}_{4}>80 \%$ after the first dose, with the level of full inhibition achieved after $8 \mathrm{~h}$. The detection limit for $\mathrm{LTE}_{4}$ in urine was $9 \mathrm{pmol} / \mathrm{L}$, which was achieved in all dose arms after multiple dosing for all subjects. Thus, only for the $60 \mathrm{mg}$ dose arm samples were analyzed for the full study period, and for the remaining doses only samples from the first dosing interval were analyzed.

\subsection{AZD5718 in Japanese and Non-Japanese Subjects}

The demographics and subject characteristics of the nonJapanese subjects included in this analysis are summarized in the Online Supplementary Material (OSM) Table 1. Mean age $( \pm \mathrm{SD})$ of the non-Japanese subjects was $36.2 \pm 6.9$ years and mean weight $( \pm$ SD) was $77.0 \pm 9.4 \mathrm{~kg}$.

The systemic exposure was similar in Japanese and nonJapanese subjects (Figs. 4, 5). As can be inferred from Fig. 5, the slight time-dependent increase in exposure is consistent between Japanese and non-Japanese subjects. Furthermore, as shown in Fig. 6, the more than dose-proportional increase in exposure is similar between Japanese and non-Japanese subjects.

The comparison of plasma $C_{\max }$ and $\mathrm{AUC}_{\tau}$ for Japanese versus non-Japanese subjects following multiple once-daily doses of $60,180,360$, and $600 \mathrm{mg}$ at Day 10 is shown in Table 3. After normalization of the pharmacokinetic parameters to a body weight of $70 \mathrm{~kg}$, exposure was similar and overlapping for Japanese and non-Japanese subjects following multiple dosing to steady state, although there was a statistically lower exposure in both $C_{\max }$ and $\mathrm{AUC}_{\tau}$ in the Japanese subjects following $60 \mathrm{mg}$ multiple dosing. The geometric mean ratios of $C_{\max }$ and $\mathrm{AUC}_{\tau}$ normalized to body 


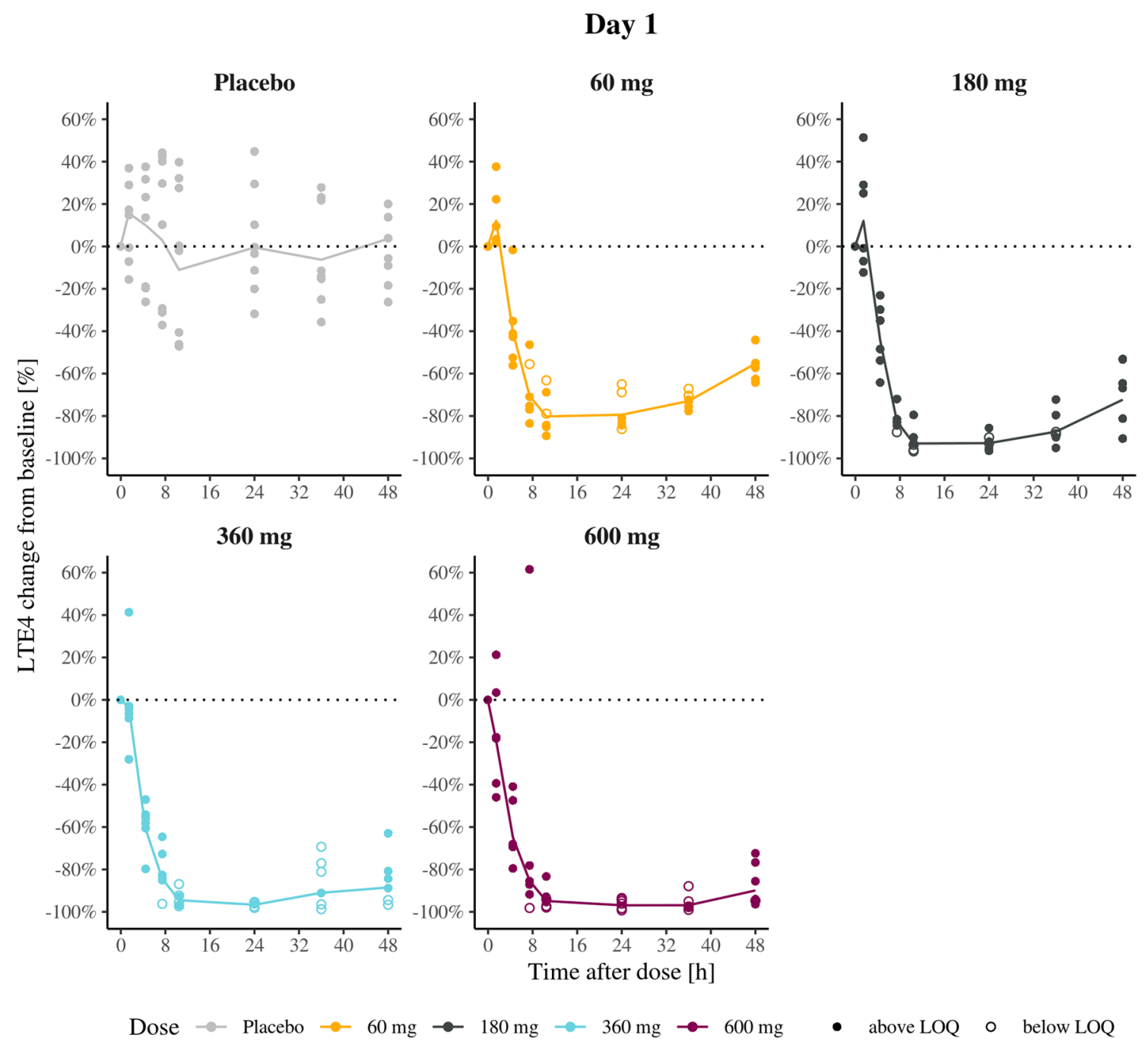

Fig. 3 Geometric mean and individual leukotriene E4 $\left(\mathrm{LTE}_{4}\right)$ inhibition-time profiles during the first $48 \mathrm{~h}$ after dose in the multiple-ascending dose administration of AZD5718 in healthy Japanese subjects, $n=6$ per arm

weight of $70 \mathrm{~kg}$ at this dose level were $63 \%$ (90\% confidence interval (CI) 48-84) and 72\% (90\% CI 55-95), respectively. However, as shown in Fig. 5, the geometric mean $C_{\text {trough }}$ values were similar at this dose level after the first dose and following repeated dosing to steady state.

The observed supra-proportional increase in exposure over the 60-600 $\mathrm{mg}$ dose range observed in Japanese subjects is generally in line with the results for the non-Japanese subjects (OSM Table 2). However, a slightly higher slope was observed for exposure for Japanese subjects at Day 10.

Figure 7 shows the geometric mean percentage change from baseline $\mathrm{LTE}_{4}$ in urine after the first dose of AZD5718 for all MAD doses in Japanese and non-Japanese subjects. Maximum reduction in $\mathrm{LTE}_{4}$ in urine was already achieved by $12 \mathrm{~h}$ post-dose in both Japanese and non-Japanese subjects. The $\mathrm{LTE}_{4}$ in urine response was generally comparable between Japanese and non-Japanese subjects, with the exception of the $60 \mathrm{mg}$ dose after the first dose. Comparison of the geometric mean percentage change from baseline $\mathrm{LTE}_{4}$ in urine for the full study length between Japanese and non-Japanese subjects for the $60 \mathrm{mg}$ dose (OSM Fig. 1) shows that the steady-state $\mathrm{LTE}_{4}$ response is comparable.

\section{Discussion}

Leukotrienes are lipid mediators derived from arachidonic acid via the action of the 5-LO pathway that have potent inflammatory and vasoactive properties [14, 15]. Leukotrienes include $\mathrm{LTB}_{4}$, a potent leukocyte activator and chemokine, and the cysteinyl leukotrienes $\left(\mathrm{LTC}_{4}, \mathrm{LTD}_{4}\right.$, and $\mathrm{LTE}_{4}$ ), potent vasoactive and inflammatory mediators. Leukotrienes have long been recognized as important players in the pathophysiology of respiratory disease including 


\section{Day 1}

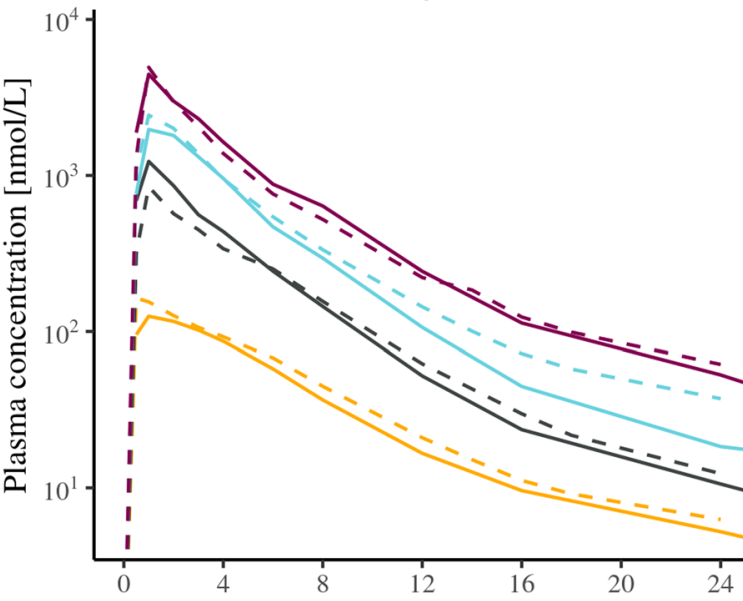

Time after dose $[\mathrm{h}]$
Day 10

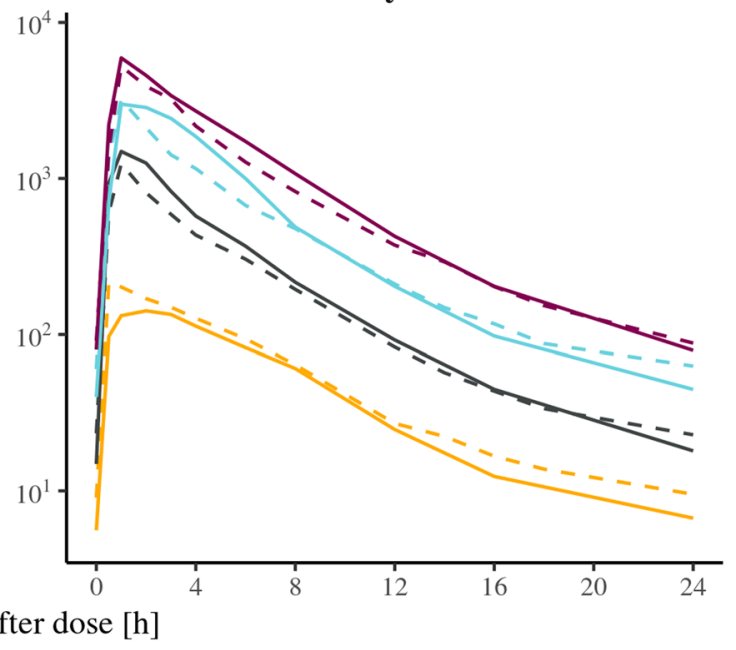

$600 \mathrm{mg} \quad$ Subjects - Japanese - - Non-Japanese

Fig. 4 Geometric mean plasma concentration-time profiles by treatment following multiple-ascending doses of AZD5718 in healthy Japanese subjects versus healthy non-Japanese subjects

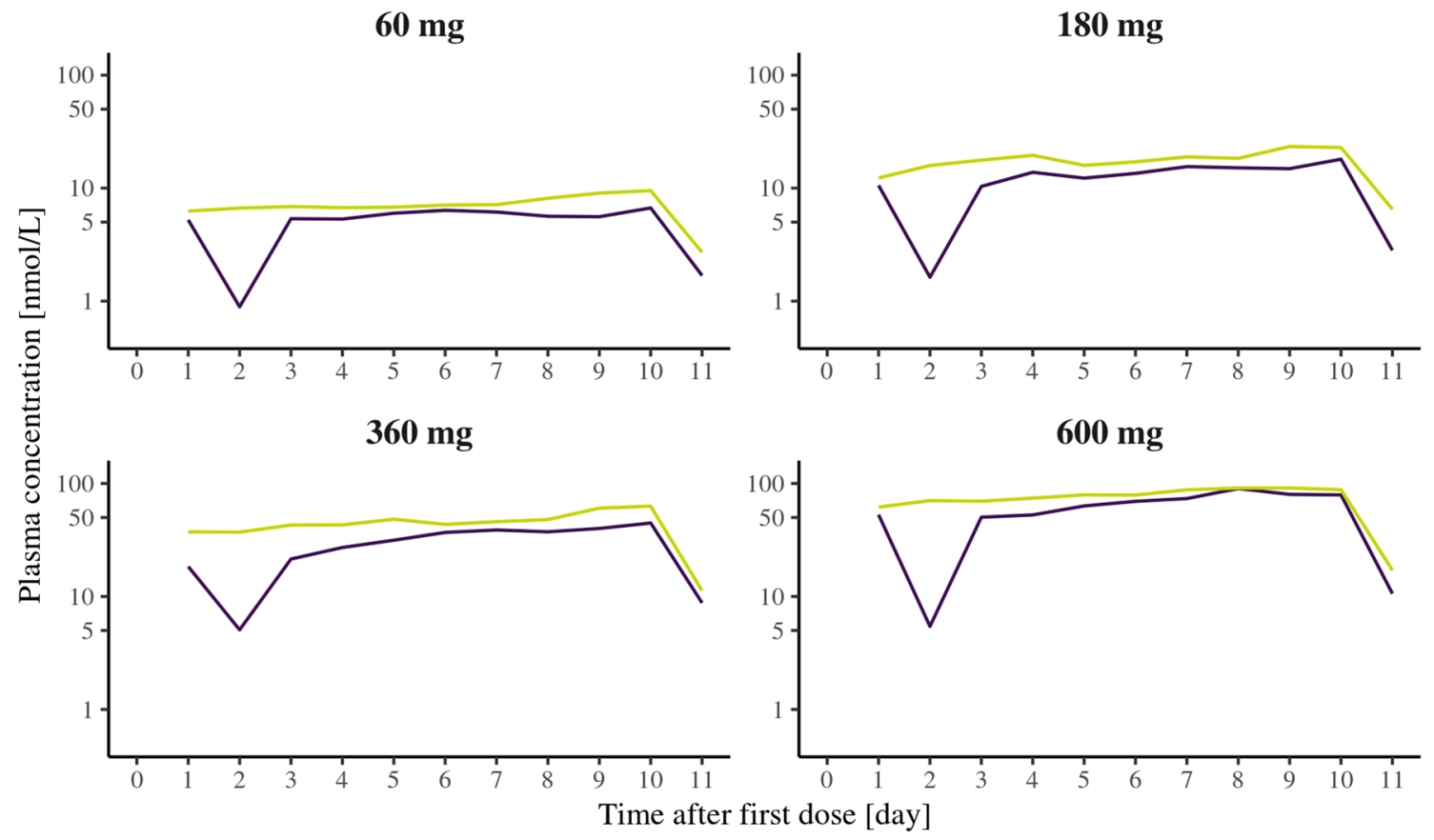

Subjects — Japanese - Non-Japanese

Fig. 5 Geometric mean trough plasma concentration-time profile by treatment following multiple ascending doses of AZD5718 in healthy Japanese subjects versus healthy non-Japanese subjects (Japanese subjects drug holiday on day 2)

asthma and rhinitis, and there is growing evidence that they could also play a role in the progression of CAD and CKD, since they could impact both inflammation and micro- and macrovascular functions. This study as well as a previously reported study have shown that AZD5718 is a potent and selective inhibitor of leukotriene production [10]. The previously reported pharmacokinetic/pharmacodynamic study was performed in mainly non-Japanese subjects [10], 


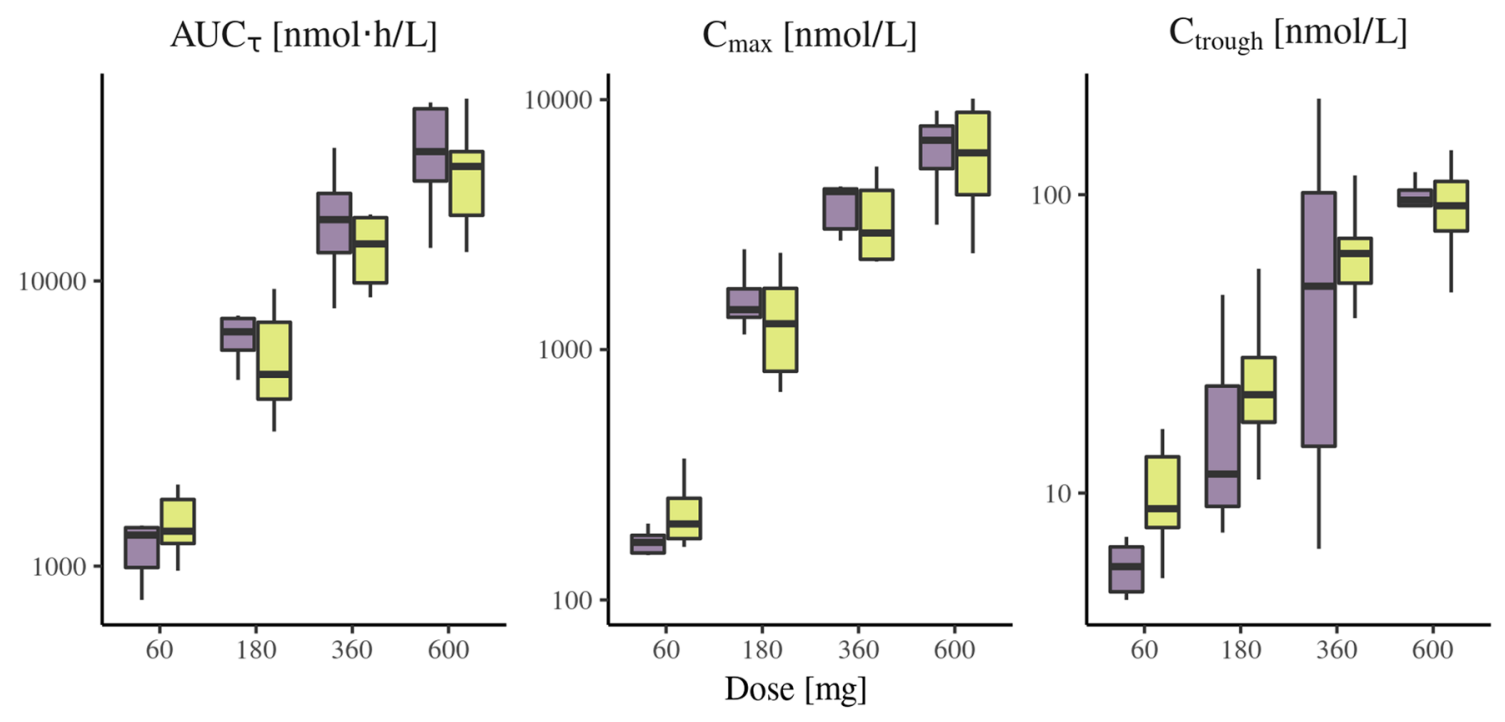

Subjects Japanese Non-Japanese

Fig. 6 Comparison of pharmacokinetic parameters area under the concentration-time curve over the dosing interval $\left(\mathrm{AUC}_{\tau}\right)$, peak plasma concentration $\left(C_{\max }\right)$, and trough plasma concentration $\left(C_{\text {trough }}\right)$ for Japanese versus non-Japanese subjects at Day $10, n=6$ per cohort. Boxplots are displayed as lower and upper hinges corre- sponding to the first and third quartiles and the bold black line represents the median. The upper and lower whiskers extend from the hinges to the largest/lowest value no further than 1.5 times the interquartile range

Table 3 Comparison of plasma $C_{\max }$ and $\mathrm{AUC}_{\tau}$ for Japanese versus non-Japanese subjects following multiple dosing of AZD5718 at Day 10

\begin{tabular}{|c|c|c|c|c|c|c|c|}
\hline \multirow[t]{2}{*}{ Parameter } & \multirow[t]{2}{*}{ Dose (mg) } & \multirow{2}{*}{$\begin{array}{l}\text { Japanese } \\
\text { geometric } \\
\text { mean }\end{array}$} & \multirow{2}{*}{$\begin{array}{l}\text { Non-Japanese } \\
\text { geometric mean }\end{array}$} & \multirow[t]{2}{*}{ GMR, $\%(90 \% \mathrm{CI})$} & \multicolumn{3}{|c|}{ Body weight normalized to $70 \mathrm{~kg}$} \\
\hline & & & & & $\begin{array}{l}\text { Japanese } \\
\text { geometric } \\
\text { mean }\end{array}$ & $\begin{array}{l}\text { Non-Japanese } \\
\text { geometric mean }\end{array}$ & GMR, \% (90\% CI) \\
\hline$C_{\max }(\mathrm{nmol} / \mathrm{L})$ & 60 & 158.9 & 219.8 & $72(54-97)$ & 147.2 & 232.3 & $63(48-84)$ \\
\hline $\mathrm{AUC}_{\tau}(\mathrm{nmol} \bullet \mathrm{h} / \mathrm{L})$ & 60 & 1140.5 & 1386.3 & $82(63-108)$ & 1056.0 & 1464.7 & $72(55-95)$ \\
\hline$C_{\max }(\mathrm{nmol} / \mathrm{L})$ & 180 & 1567.9 & 1243.2 & $126(82-195)$ & 1374.9 & 1415.0 & $97(65-145)$ \\
\hline $\mathrm{AUC}_{\tau}(\mathrm{nmol} \bullet \mathrm{h} / \mathrm{L})$ & 180 & 6724.5 & 5128.4 & $131(88-196)$ & 5896.7 & 5837.1 & $101(71-144)$ \\
\hline$C_{\max }(\mathrm{nmol} / \mathrm{L})$ & 360 & 3461.5 & 3209.2 & $108(72-162)$ & 3272.4 & 3682.6 & $89(60-131)$ \\
\hline $\mathrm{AUC}_{\tau}(\mathrm{nmol} \bullet \mathrm{h} / \mathrm{L})$ & 360 & $15,847.3$ & $12,764.7$ & $124(83-186)$ & $14,981.4$ & $14,647.6$ & $102(70-149)$ \\
\hline$C_{\max }(\mathrm{nmol} / \mathrm{L})$ & 600 & 6145.6 & 5692.8 & $108(66-178)$ & 5818.4 & 6130.5 & $95(64-142)$ \\
\hline $\mathrm{AUC}_{\tau}(\mathrm{nmol} \bullet \mathrm{h} / \mathrm{L})$ & 600 & $27,349.3$ & $23,175.0$ & $118(73-190)$ & $25,893.0$ & $24,956.5$ & $104(69-156)$ \\
\hline
\end{tabular}

$A U C_{\tau}$ area under the concentration-time curve over the dosing interval, $C_{\max }$ peak plasma concentration, $G M R$ geometric mean ratio, $C I$ confidence interval

and, as these parameters can vary in different ethnicities [15], the objective of this study was to assess the safety, tolerability, and pharmacokinetics/pharmacodynamics of AZD5718 following oral administration of single- and multiple-ascending doses (SMADs) of AZD5718 in healthy Japanese subjects. The results from this study formed the basis for the identical doses to be evaluated in the ongoing dose-finding study in Japanese and non-Japanese CKD patients (NCT04492722, FLAIR study [16]).

As previously reported for healthy non-Japanese subjects [10], most pharmacokinetics parameters of AZD5718 exposure increased in a more than dose-proportional manner. In contrast, dose-proportionality was observed in $C_{\text {trough }}$. The more than dose-proportional increase in exposure is not fully understood, but likely explained by saturation of efflux and/ or metabolism during absorption/first pass of AZD5718. This hypothesis is supported by the unchanged half-life and constant and dose-proportional $\mathrm{C}_{\text {trough }}$ concentrations over time.

Both $C_{\max }$ and $\mathrm{AUC}_{\tau}$ were slightly higher in Japanese versus non-Japanese subjects, with the exception of the $60 \mathrm{mg}$ dose arm. This finding was mainly explained by differences in body weight as after normalization to body 


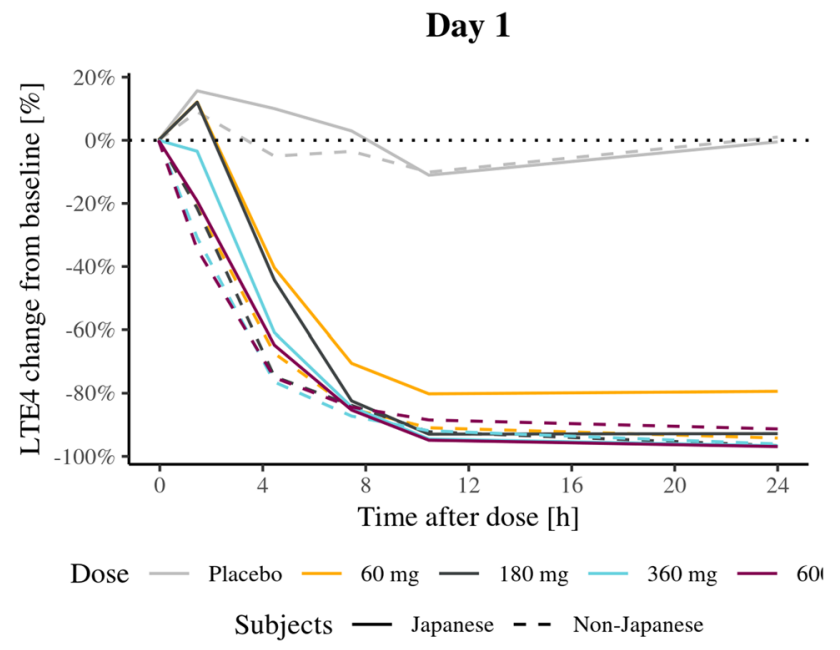

Fig. 7 Geometric mean leukotriene E4 (LTE $)$ inhibition-time profiles following multiple-ascending doses (MADs) of AZD5718 in Japanese (full) and non-Japanese (dashed) subjects, $n=6$ per arm

weight, the differences were minimal for all doses with the exception the lowest dose. For the rest of the dose levels evaluated, there were no differences in exposures between healthy Japanese and non-Japanese subjects following dose normalization to the same body weight.

The onset of reduction in $\mathrm{LTE}_{4}$ in urine was observed to be dose dependent in healthy Japanese subjects. The achieved change from baseline in $\mathrm{LTE}_{4}$ in urine was in general similar between Japanese and non-Japanese subjects with the exception of the $60 \mathrm{mg}$ dose arm. This is in agreement with the small differences in pharmacokinetics, but the steady-state reduction in $\mathrm{LTE}_{4}$ in urine for that dose arm was similar between the two groups.

Possible limitations of this study are the exclusive inclusion of male subjects and study conduct outside of Japan. The reason for the exclusion of women in this study was the limited reproductive toxicology data available and thus women of childbearing potential were excluded in the initial SMAD study [10]. Due to the small sample size and to reduce potential variability, women were excluded in this study as well. However, the generated data provide information for future studies in the target patient population. Concerning study conduct outside of Japan, the inclusion criteria in this study specified Japanese subjects who had not lived outside of Japan for more than 10 years. Differences in environment and potentially diet could thus have affected the results.

\section{Conclusion}

In summary, single and multiple doses of AZD5718 were safe, well tolerated, and yielded more than dose-proportional increases in AUC and $C_{\max }$ whereas $C_{\text {trough }}$ increased proportional to dose in Japanese healthy subjects. A sustained reduction in $\mathrm{LTE}_{4}$ in urine above $80 \%$ was observed for all doses. Considering the similarities in pharmacokinetic and pharmacokinetic/pharmacodynamic characteristics between Japanese and reported non-Japanese subjects, the data support further development of similar doses of AZD5718 in Japanese and non-Japanese CAD or CKD patients.

Supplementary Information The online version contains supplementary material available at https://doi.org/10.1007/s40261-021-01078-7.

\section{Declarations}

Funding AstraZeneca provided funding to PAREXEL for the conduct of this study.

Conflicts of interest J.K, K.N, M.H, E.-L.L,G.-B.F, C.W, H.S, A.G, P.G, and H.E are all employees of AstraZeneca. D.H. is employed by Parexel.

Ethics approval The study was approved by Aspire Institutional Review Board and was conducted in accordance with the Declaration of Helsinki following Good Clinical Practice Guidelines.

Consent to participate Study participants provided written informed consent.

Consent for publication Not applicable.

Availability of data and material The authors confirm that all relevant data supporting the findings are included in this article and/or its supplementary information file.

Code availability Not applicable.

Open Access This article is licensed under a Creative Commons Attribution-NonCommercial 4.0 International License, which permits any non-commercial use, sharing, adaptation, distribution and reproduction in any medium or format, as long as you give appropriate credit to the original author(s) and the source, provide a link to the Creative Commons licence, and indicate if changes were made. The images or other third party material in this article are included in the article's Creative Commons licence, unless indicated otherwise in a credit line to the material. If material is not included in the article's Creative Commons licence and your intended use is not permitted by statutory regulation or exceeds the permitted use, you will need to obtain permission directly from the copyright holder. To view a copy of this licence, visit http://creativecommons.org/licenses/by-nc/4.0/.

\section{References}

1. Helgadottir A, Manolescu A, Thorleifsson G, et al. The gene encoding 5-lipoxygenase activating protein confers risk of myocardial infarction and stroke. Nat Genet. 2004;36(3):233-9. https://doi.org/10.1038/ng1311.

2. Hao CM, Breyer MD. Roles of lipid mediators in kidney injury. Semin Nephrol. 2007;27(3):338-51. https://doi.org/10.1016/J. SEMNEPHROL.2007.02.008. 
3. Rubinstein M, Dvash E. Leukotrienes and kidney diseases. Curr Opin Nephrol Hypertens. 2018;27(1):42-8. https://doi.org/10. 1097/MNH.0000000000000381.

4. Yasuda Y, Cohen CD, Henger A, Kretzler M. Gene expression profiling analysis in nephrology: towards molecular definition of renal disease. Clin Exp Nephrol. 2006;10:91-8. https://doi.org/ 10.1007/s10157-006-0421-z.

5. Lemurell M, Ulander J, Emtenäs H, et al. Novel chemical series of 5-lipoxygenase-activating protein inhibitors for treatment of coronary artery disease. J Med Chem. 2019;62(9):4325-49. https:// doi.org/10.1021/acs.jmedchem.8b02012.

6. Depré M, Friedman B, Van Hecken A, et al. Pharmacokinetics and pharmacodynamics of multiple oral doses of MK-0591, a 5-lipoxygenase-activating protein inhibitor. Clin Pharmacol Ther. 1994;56(1):22-30. https://doi.org/10.1038/clpt.1994.96.

7. Hakornarson H, Thorvaldsson S, Helgadottir A, et al. Effects of a 5-lipoxygenase-activating protein inhibitor on biomarkers associated with risk of myocardial infarction. JAMA. 2005;293(18):2245-56.

8. Bain G, King CD, Rewolinski M, et al. Pharmacodynamics and pharmacokinetics of AM103, a novel inhibitor of 5-lipoxygenaseactivating protein (FLAP). Clin Pharmacol. 2010;87(4):437-44. https://doi.org/10.1038/clpt.2009.301.

9. Pettersen D, Davidsson Ö, Whatling C. Recent advances for FLAP inhibitors. Bioorg Med Chem Lett. 2015;25(13):2607-12. https:// doi.org/10.1016/J.BMCL.2015.04.090.
10. Ericsson H, Nelander K, Lagerstrom-Fermer M, et al. Initial clinical experience with AZD5718, a novel once daily oral 5-lipoxygenase activating protein inhibitor. Clin Transl Sci. 2018;11(3):330 8. https://doi.org/10.1111/cts.12546.

11. Ericsson H, Nelander K, Heijer M, et al. Phase 1 pharmacokinetic study of AZD5718 in healthy volunteers: effects of coadministration with Rosuvastatin, er. Clin Pharmacol Drug Dev. 2020;9(3):411-21. https://doi.org/10.1002/cpdd.756.

12. Hall J, Gillen M, Liu S, et al. Pharmacokinetics, pharmacodynamics, and tolerability of verinurad, a selective uric acid reabsorption inhibitor, in healthy Japanese and non-Asian male subjects. Drug Des Devel Ther. 2018;12:1799-807. https://doi.org/10.2147/ DDDT.S152659.

13. Al-sallami HS, Cheah SL, Han SY, et al. Between-subject variability: should high be the new normal? Eur J Clin Pharmacol. 2014;70:1403-4. https://doi.org/10.1007/s00228-014-1740-8.

14. Peters-Golden M, Henderson WR. Leukotrienes. N Engl J Med. 2007;357(18):1841-54. https://doi.org/10.1177/1461444810365020.

15. Yasuda SU, Zhang L, Huang S. The role of ethnicity in variability in response to drugs: focus on clinical pharmacology studies. Clin Pharmacol Ther. 2008;84(3):417-23. https://doi.org/10.1038/clpt. 2008.141.

16. Heersprink HJL, Law G, Pschaoulia K, et al. Design of FLAIR: a phase $2 \mathrm{~b}$ study of the 5-lipoxygenase-activating protein inhibitor AZD5718 in patients with proteinuric chronic kidney disease. Kidney Int Rep. 2021. https://doi.org/10.1016/j.ekir.2021.08.018 